\title{
A atuação do Estado frente à indústria mineradora em Conceição do Mato Dentro/MG como instrumento de (in) efetivação do texto constitucional
}

\section{The acting of the State in front of the mining industry at Conceição do Mato Dentro / MG as an instrument of (in)effectiveness of the constitutional text}

\author{
Larissa Pirchiner de Oliveira Vieira \\ Mestranda em Arquitetura e Urbanismo pela UFMG \\ larissapov@gmail.com \\ Juliana Benício Xavier \\ Mestranda em Direito Público pela PUC-Minas \\ jubenicio@hotmail.com
}

\begin{abstract}
Resumo: O Estado brasileiro incentiva a atividade mineradora como uma das principais atividades econômicas do país. Torna-se, portanto, relevante aprofundar os estudos acerca da mineração enquanto atividade econômica supostamente propulsora de desenvolvimento regional e nacional. A partir da análise do Projeto Minas-Rio, que envolve a extração de minério no município mineiro de Conceição do Mato Dentro, e construção de mineroduto até o Porto do Açu em São João da Barra/RJ, verifica-se a repetição de um modelo econômico que na prática traz mais atraso que de fato, desenvolvimento. Necessário, também, o estudo da forma de atuação do Estado frente aos conflitos gerados pela execução da referida atividade. Observa-se que este ainda não chamou para si as tarefas que lhe são inerentes, no tocante à fiscalização e controle do exercício da atividade, apurando irregularidades das empresas mineradoras e punindo-as corretamente. $\mathrm{O}$ que se percebe são os interesses dos grupos econômicos prevalecendo sobre os direitos individuais e coletivos da população, motivo pelo qual relevante é o presente estudo.
\end{abstract}

Palavras chave: Mineração. Desenvolvimento. Conflitos. Interesses. Direitos.

\begin{abstract}
The Brazilian government encourages mining as an axis of economic activity in this country. In this context, it becomes extremely important to deepen the studies on mining as an economic activity that intends to promote the development of a region or a country like Brazil. Based on the analysis of the Minas-Rio Project, which involves the extraction of ore in the mining town of Conceição do Mato Dentro and the construction of a pipeline to the Açu Port in in São João da Barra/RJ is verified that it is repeating an economic model already tested numerous times and in all attempts proved to be harmful to the affected populations. Moreover, it is necessary to study the form of state action front of conflicts caused by the operation of the mining activity. The Brazilian State has not called to himself tasks that are inherent to its activities, as regards the monitoring and controlling activities. There are a prevail of interests of economic groups against achievement of individual and collective rights. To accomplish such a task, it is essential that the State dialogues with the population, that comes close to those affected by a project of the magnitude of the Minas Rio project and listen so as to understand how they see the activity and what their expectations in relation to the same.
\end{abstract}

Keywords: Mining. Development. Conflict. Interests. Rights.

Originais recebidos em: 23/03/2014

Aceito para publicação em: 27/06/2014

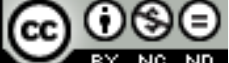

Comercial-Vedada a criação de obras derivadas 3.0 Unported License. 


\section{Introdução}

Historicamente, a região de Minas Gerais é conhecida por sua indústria extrativa relacionada à mineração. Desde meados do século XVII, a região rica em recursos naturais está ligada à exportação de minério. A experiência da atividade minerária na cidade de Ouro Preto, interior de Minas Gerais é uma das primeiras de que se tem notícia. Não se pode dizer, contudo, que os resultados, trouxeram desenvolvimento, já que em pouco tempo se tinham praticamente esgotado os depósitos superficiais, sem nada se acumular para a população local.

Passados quase dois séculos, o Brasil nada parece ter acumulado com as experiências anteriores sobre os prejuízos de exercer uma atividade mineradora de forma desgovernada, sem fiscalização, regulação e participação da sociedade. O Estado, em conjunto com as empresas privadas mineradoras, tenta ganhar o apoio da população com o discurso do desenvolvimento, mas o que a história demonstra é que os mega empreendimentos de mineração em cidades interioranas trazem apenas ônus para a população local. E se trazem algum benefício, este é pequeno diante dos prejuízos causados. É o caso de cidades mineiras como Raposos, Itabira e agora Conceição do Mato Dentro.

Nesse sentido, é necessário questionar se a atividade mineradora realmente é importante para fomentar o desenvolvimento no país, além de se avaliar para quem se está promovendo esse tão falado desenvolvimento e qual tipo de desenvolvimento é esse.

Ademais, deve-se perquirir qual deve ser a atuação do Estado enquanto ente garantidor de direitos individuais e coletivos, protetor do meio ambiente, fiscalizador e regulador da atividade econômica.

\section{A mineração na economia brasileira}

Nas últimas décadas, o setor da mineração cresceu três vezes mais do que os demais setores industriais. Segundo o relatório de uma das maiores prestadoras de serviços profissionais do mundo de auditoria e consultoria para empresas, a PricewaterhouseCoopers (PwC), de 2006, "Estamos em um boom da mineração". (PwC, 2006) 
O crescimento do setor mineral ao longo das últimas décadas pode estar diretamente ligado à satisfação das necessidades de uma sociedade cada vez mais movida pelo consumo, contribuindo assim para a manutenção do sistema capitalista.

A atividade mineradora demanda altos investimentos de capitais em pesquisa, prospecção, industrialização e comercialização, sendo que boa parte da produção mineral é comandada atualmente pelo setor privado, principalmente por grandes empresas que contam com financiamento internacional.

O crescimento da demanda por minério de ferro faz com que a exploração desse recurso não renovável torne-se um negócio altamente lucrativo, mas ao mesmo tempo instável.

Se, de um lado, ao longo das últimas décadas as ações das empresas mineradoras estiveram em alta, chegando o ano de 2006 a ser considerado o "boom" da mineração, essa tendência modificou-se recentemente, demonstrando a instabilidade típica do setor.

Segundo também o relatório da PricewaterhouseCoopers (PwC), em 2012, "o valor de mercado das mineradoras teve ligeira queda, trajetória que se intensificou este ano. Nos quatro primeiros meses de 2013, a queda é de quase $20 \%$, segundo a análise dos resultados das 40 maiores mineradoras do mundo." (PwC, 2013)

Acredita-se que parte dessa suposta crise enfrentada pelo setor mineral se deva à incerteza dos investidores quanto à incapacidade de controlar custos, de melhorar o retorno sobre o capital e de que os preços das "commodities" não entrem em colapso comprometendo os resultados. (PwC, 2013)

Contudo, apesar do suposto momento de crise, a indústria da mineração segue sendo um setor relevante para a economia mundial, e também para o Brasil.

Nada obstante seu imenso potencial, a mineração em grande parte da história brasileira foi controlada por grupos econômicos internacionais até mesmo no período em que a Vale do Rio Doce foi estatal. (GODEIRO, 2007, p. 31).

Mas, foi especialmente com a privatização da Companhia Vale do Rio Doce que se iniciou um novo ciclo na história da mineração brasileira, que hoje, como dito, tem a iniciativa privada como sua principal propulsora.

Assim, se antes o Estado atuava diretamente na economia, cumprindo o papel de empreendedor e gerenciador dessa atividade mineral, agora age essencialmente de forma a incentivar, regulamentar e "fiscalizar" esta atividade. (DNPM, 2000)

O próprio Departamento Nacional de Produção Mineral, através de manual divulgado na internet, "convida, mais uma vez, a iniciativa privada a explorar e 
desenvolver, com o apoio do Governo Federal, o imenso potencial mineral deste país." (DNPM, 2000)

Tamanho incentivo levou o Brasil a ter, juntamente com a Austrália, a maior participação na produção mundial do minério de ferro, sendo que em 2007, os dois países eram responsáveis por $44 \%$ da produção mundial (28\% na Austrália e 16\% no Brasil); em 2012, esse índice chegou a 63\% (45\% na Austrália e 18\% no Brasil). (PwC, 2013)

Em termos de produto interno bruto, verifica-se no ano de 2000, que a indústria extrativa representava 1,6\% do PIB brasileiro; em dez anos, esse percentual alcançou 4,1\%. Da mesma forma, a participação dos minérios nas exportações saltou de $7,1 \%$ em 2006 para 17,3\% em 2011. (REVELLI, 2012).

Assim, em termos econômicos, é inegável a importância da indústria mineradora para nosso país. Mas não só para nosso país, a mineração é uma das principais fronteiras econômicas do estado de Minas Gerais, conhecido como maior e mais tradicional estado minerador do país.

O estado destaca-se no cenário nacional como o principal produtor de minerais metálicos e não-metálicos do país, respondendo por $35 \%$ do total da mineração brasileira sendo que o principal minério extraído é o de ferro. (EXPORTAMINAS, 2013)

Atualmente, o estado recebe inúmeros investimentos estrangeiros no setor, inclusive um dos maiores e mais complexos projetos de mineração do mundo, o Projeto Minas-Rio, implementado no Município de Conceição do Mato Dentro.

Do ponto de vista da geração do aumento de impostos, no entanto, tal atividade não tem sido tão expressiva, vez que a Compensação Financeira para Exploração de Recursos Minerais - CEFEM - atualmente chega a no máximo 3\% do faturamento líquido das empresas.

Em se tratando da geração de empregos, há que se considerar que muitas vezes as cidades que recebem o empreendimento minerário não possuem mão de obra suficiente, seja quantitativamente, seja qualitativamente. Ademais, tratam-se de empregos transitórios que não perduram ao fim da atividade mineradora e que dependem da volatilidade do setor minerário, além de serem extremamente precarizados.

A despeito da relativa importância da atividade para a economia brasileira, há que se questionar os investimentos excessivos no setor, além do incentivo por parte dos Em Debat: Rev. Dig., ISSNe 1980-3532, Florianópolis, n. 9, p. 74-89, jan-jun, 2013. 
poderes constituídos que entendem e pregam a referida atividade como sinônimo de desenvolvimento no país. A pergunta que se deve fazer é onde, para quem e de qual tipo é esse tão falado desenvolvimento.

\section{Mineração, subdesenvolvimento e dependência}

O discurso capitalista hegemônico hoje é firme ao dizer que a atividade mineradora é importante para o país e é propulsora do desenvolvimento, já que gera arrecadação de impostos, emprego e renda.

Sem entrar em detalhes sobre o conceito de desenvolvimento difundido hoje, é preciso fazer breves considerações sobre a atividade mineradora, o desenvolvimento, o subdesenvolvimento e a dependência.

Como destacado anteriormente, inegável é a importância da atividade mineradora para o Brasil. Nada obstante, há que se questionar os excessivos investimentos e incentivos no setor mineral, bem como se a exportação das “commodities" poderiam gerar o tão falado desenvolvimento.

Pois como dito oportunamente ao mesmo tempo em que se trata de um negócio altamente lucrativo, a atividade mineradora sustentada pela exportação das “commodities" é instável.

Gabriel Palma, especialista em desenvolvimento econômico e América Latina, critica a visão "excessivamente otimista" para com a economia brasileira. Defende que esse otimismo é sustentado artificialmente pelos preços elevados das "commodities", além do forte ingresso de capitais estrangeiros, impulsionados por um mundo em crise. Diz que o Brasil tem crescido sobre bases que o governo não tem controle, como o fluxo de capitais externos e os preços das "commodities", de modo que na hora que isso mudar de mão, o Brasil terá sérios problemas. (PALMA, 2012.)

Desse modo, sustentar um "desenvolvimento econômico" que é dependente dos preços das “commodities" é no mínimo questionável. Esse cenário configura uma situação de dependência, que por sua vez pode levar à subordinação.

Ruy Mauro Marini em "Dialética da Dependência" resume a relação de dependência da seguinte forma:

A dependência é uma relação de subordinação entre nações formalmente independentes, em cujo marco das relações de produção das nações subordinadas são modificadas ou recriadas para assegurar a reprodução da dependência ampliada. O mero fato de que algumas nações industriais 
produzam bens que as demais não produzem, permite que as primeiras elucidem a lei do valor, isso é, vendam seus produtos a preços superiores a seu valor, configurando um intercâmbio desigual. Isto implica que as nações desfavorecidas devam ceder gratuitamente parte do valor que produzem. A função cumprida pela América Latina no desenvolvimento do capitalismo mundial foi de fornecer bens pecuários aos países industriais, e de contribuir para a formação de um mercado de matérias primas industriais. (MARINI, 2000, p. 109.)

A dependência para Marini se resumiria, portanto, a uma situação em que uma economia está condicionada pelo desenvolvimento e expansão de outra. Isso estaria bem resumido em se tratando de países periféricos e centrais.

Nesse sentido, bem cita o autor o exemplo da América Latina que cumpriu um papel importantíssimo no desenvolvimento do capitalismo mundial, fornecendo bens pecuários e matérias primas industriais para as centralidades.

Marini destaca ainda três condicionantes básicas, quais sejam: a redução dos preços dos produtos exportados pelos países dependentes, a remessa de excedentes para o centro capitalista por meio de juros, lucros, amortizações, dividendos e royalties, já que esses países importam tecnologias avançadas, e a instabilidade dos mercados financeiros internacionais, o que afeta principalmente os países periféricos pelas altas taxas de juros no crédito.

Com base nisso, o Brasil, ao subsidiar cada vez mais a economia mineradora, seria dependente em relação ao capitalismo central, já que realiza trocas, por exemplo, de "commodities" ou produtos primários (no caso o minério), por produtos com alto valor agregado, o que somente aumenta sua condição de dependente e subdesenvolvido.

De acordo cm essa teoria, portanto, o subdesenvolvimento não seria, ao contrário do discurso hegemônico, resultado da incompetência de alguns governos, mas seria necessário para o desenvolvimento do próprio capitalismo, já que para a existência do "desenvolvido" é necessário existir o "subdesenvolvido".

Por outro lado, sabe-se que o desenvolvimento de um país não se mensura pelo simples crescimento econômico mesmo quando ele é prolongado. Assim, mesmo o Brasil sendo uma das dez maiores economias do mundo (BRASIL, 2012).

Não se pode dizer que se trata de um país desenvolvimento, tendo em vista que persiste a enorme concentração de renda e índices significativos de pobreza e miséria.

Para Denise de Castro Pereira e Luciana Felício Pereira:

Se por um lado a atividade minerária anuncia a aceleração do crescimento econômico, com aumento de empregos, ampliação das cadeias de negócios do seu entorno, aumento de impostos e a Compensação Financeira pela Exploração de Recursos Minerais, por outro, as análises socioambientais revelam uma gama de problemas, como: a desterritorialização de parcela da

Em Debat: Rev. Dig., ISSNe 1980-3532, Florianópolis, n. 9, p. 74-89, jan-jun, 2013. 
população local, reestruturação fundiária pela apropriação de território pelo empreendimento; indenizações e reassentamentos de famílias e/ou de núcleos comunitários; deslocamentos de processos produtivos locais; fluxos migratórios intensos, com a presença de contingentes significativos de trabalhadores temporários, geradores novas relações sociais; relações de dependência e possibilidade de obscurecer a perspectiva de desenvolvimento local quando a exploração mineral centraliza a economia; não garantia de condições para a continuidade de fluxos econômicos nem de qualidade de vida da população local nos planejamentos empresariais; fragilidade na articulação de políticas públicas locais para a construção de alternativas para economia e a comunidade local; cidades esvaziadas pela paralisação das atividades minerárias. (PEREIRA e PEREIRA, 2012)

Ora, mas como se falar em desenvolvimento se a região fica, na maioria das vezes economicamente dependente da atividade mineradora? Como se falar em desenvolvimento se o meio ambiente está sendo devastado, se os direitos da população estão sendo violados, se os índices de pobreza, desigualdade e segregação aumentam?

\section{O "desenvolvimento" em regiões afetadas pela mineração: foco em experiências no estado de minas gerais}

O Estado brasileiro, em conjunto com as empresas privadas mineradoras, prega o discurso de que a mineração traz desenvolvimento. De outro lado, as histórias mundial e brasileira mostram que os megaprojetos de empreendimentos de mineração, que na maioria das vezes se dá em cidades inexpressivas e com baixa densidade populacional, trazem apenas ônus para essa população local, diretamente atingida. E se trazem algum benefício, esse é pequeno diante dos prejuízos causados. É o caso de cidades mineiras como Raposos, Itabira e agora Conceição do Mato Dentro.

A cidade de Ouro Preto/MG que começa sua história de exportação dos recursos naturais em meados do século XVII deve ser sempre lembrada, pois é exemplo claro de que a descoberta de recursos naturais não necessariamente traz desenvolvimento local. Isso porque "chega-se em fins do século XVIII a um momento em que já se tinham esgotado praticamente todos os depósitos superficiais em toda a vasta área em que ocorreram. A mineração sofre então seu colapso final. Nada se acumulara na fase mais próspera para fazer frente à eventualidade.” (PRADO Jr, 1984, p.62)

Passados quase dois séculos, as experiências não se modificaram muito, tendo em vista que na cidade de Raposos/MG, a atividade mineraria, ao contrário do desenvolvimento, causou ainda mais dependência econômica:

A dependência econômica do quadrilátero ferrífero mineiro em relação à atividade mineira-exportadora faz com que inúmeras localidades desta região

Em Debat: Rev. Dig., ISSNe 1980-3532, Florianópolis, n. 9, p. 74-89, jan-jun, 2013. 
sobrevivam, quase, exclusivamente da mineração. A cidade de Raposos é, hoje em dia, uma cidade dormitório, e sua população jovem busca emprego em outros municípios. A cidade se encontra em declínio econômico desde o fechamento da mina de Raposos em 1998. A especialização na mineração se mostra em longo prazo prejudicial, visto que a população local torna-se dependente dos poucos empregos criados por uma atividade que tem prazo de validade. Com a infra-estrutura da região o lucro no curto prazo é possível apenas para as mineradoras que, dessa forma, serão as únicas a terem intenção de investirem na região. Assim, a população local se vê envolta numa "minério-dependência" que têm implicações além de econômicas, também, sociais e culturais. (COELHO, 2012, p. 140).

A cidade de Itabira depende hoje aproximadamente de $60 \%$ da atividade minerária para sua sobrevivência. (BRASIL, 2012)

Mas a atividade mineradora não só fez com que a cidade se tornasse dependente economicamente da atividade mineradora como também lhe trouxe uma mudança no cenário:

Não há como não se impressionar com as enormes e profundas crateras escavadas ao longo de décadas de exploração do ferro em Itabira. A grandiosidade dos buracos é tanta que imensas máquinas quase se perdem dentro deles enquanto trabalham. (BRASIL, 2012)

Cenários devastados, população esquecida e economia mais dependente do que nunca. Estes foram os legados deixados por megaprojetos de mineração em cidades do interior de Minas Gerais como Ouro Preto, Itabira e Raposos.

E, da forma como vem acontecendo a implantação do Projeto Minas Rio em Conceição do Mato Dentro, nova "menina dos olhos" da mineração no estado de Minas Gerais em pouco tempo a Serra da Ferrugem, em Conceição do Mato Dentro, dará lugar a um cenário semelhante ao das cidades anteriormente citadas.

A empresa responsável pela atividade mineradora na região, antes mesmo de obter o licenciamento ambiental para operar, já tem causado sérios danos à cidade e população local. Aliás, é importante mencionar que:

As características críticas do processo de licenciamento ambiental geraram uma avalanche de medidas condicionantes sendo: na Licença Prévia (LP), em 2008, 101 medidas condicionantes entre itens e subitens, sendo destas 33 específicas ao empreendimento; 12 relativas ao meio biótico; 56 relativas ao meio socioeconômico, além de 2 condicionantes da COPASA, 6 condicionantes do IBAMA e 6 condicionantes gerais. Em síntese, o não cumprimento efetivo e integral de tais condicionantes gerou a fragmentação da Licença de Instalação (LI) em 2 fases (LI Fase 1 e LI Fase 2). (...) Tendo em vista a redefinição e os ajustes em condicionantes, negociadas e aprovadas pelo conselho da URC-Jequitinhonha chegou-se a mais de 270 condicionantes, o que caracteriza os percalços e falhas do processo de gerenciamento do empreendimento frente às exigências legais e o respeito à construção social local. (PEREIRA e PEREIRA, 2012)

O descumprimento pela empresa "Anglo American" das condicionantes do licenciamento ambiental do empreendimento ainda na fase de sua instalação permite 
antever o que pode ocorrer com a atividade mineradora exercida de forma desgovernada, unicamente preocupada em gerar lucro para seus acionistas.

E por falar em lucro, importante relembrar que a Companhia Vale do Rio Doce que após a aquisição da Inco se tornou a segunda maior empresa mineradora do mundo, "bateu seus recordes no ano de 2008, lucrou US\$ 13,3 bilhões e distribuiu US\$ 2,75 bilhões aos seus acionistas, uma quantia maior que aquela gasta com os salários US\$ 1,9 bilhão.” (REVELLI, 2010)

\section{Sobre o papel do estado como ente regulador da atividade econômica}

É bom deixar assentado, nesse ponto da reflexão, que garantir em seu documento instituidor a defesa do meio ambiente é tarefa de um Estado que deixa o viés liberal e ressurge assumindo sua vocação de atuar no campo econômico, voltado não somente à função de produção do direito e segurança, mas também às funções de substituição e compensação do mercado. Essa assunção de novas tarefas pelo Estado tem lugar frente ao desmoronamento da "hipocrisia liberalista fundada na compreensão de que a liberdade e a vida estariam garantidas simplesmente porque o Estado não atentaria contra elas." (CLARK, e XAVIER, 2012)

Neste sentido, Eros Grau (GRAU, 2012, p.20) identifica quatro categorias de atividade estatal dentro do paradigma do Estado Moderno, sendo elas: 1) constituição e preservação do modo de produção; 2) a complementação do mercado; 3 ) substituição do mercado; e 4) compensação de disfunções do processo de acumulação. Dentro desta última categoria estaria a atividade estatal voltada à preservação ambiental e à minimização dos danos ambientais oriundos da atividade econômica. Essa "nova" preocupação do Estado resulta diretamente da necessidade de adaptação do capitalismo, na tentativa de se defender dos frutos de sua atuação inerentemente autodestrutível.

$\mathrm{O}$ mesmo texto constitucional que assegura o direito à vida elege como fundamento da República a livre iniciativa (art. $1^{\circ}, \mathrm{IV}, \mathrm{CR} / 88$ ) e coloca a propriedade privada como princípio da ordem econômica. Na tentativa de compatibilizar fundamentos e objetivos tão díspares, o ordenamento jurídico brasileiro elegeu como princípio o desenvolvimento sustentável, diretamente decorrente do princípio da função social da propriedade (art. 170, III, CR/88), segundo o qual não se pode priorizar o direito de propriedade em detrimento do interesse coletivo. 
Esse instituto determina que a utilização da propriedade privada se faça em sintonia com a preservação ambiental. A Constituição da República de 1988, segundo Moraes (MORAES, 2010, p. 847), “consagrou como obrigação do Poder Público, a defesa, preservação e garantia de efetividade do direito fundamental ao meio ambiente ecologicamente equilibrado, bem de uso comum do povo e essencial à sadia qualidade de vida".

Nessa perspectiva, é importante se ter em mente o princípio do desenvolvimento sustentável, tão caro ao direito ambiental. Esse princípio pode ser concebido como um poder-dever de cada indivíduo realizar as suas potencialidades, garantindo quando desta realização, que as futuras gerações tenham as mesmas condições de sobrevivência que as presentes. É uma garantia de que os seres humanos de hoje realizarão suas atividades conservando o locus para que os que ainda nascerão tenham a possibilidade de viver com qualidade.

Um instituto de observação importante, parceiro do conceito de sustentabilidade, é o que determina que toda a propriedade deva atender à função social, ou seja, impõe que não se pode priorizar o direito de propriedade em detrimento do interesse coletivo. Esse instituto permite uma interpretação que garanta a utilização dos recursos naturais disponíveis em sintonia com a preservação ambiental.

Evidente, portanto, que ao Estado Moderno estão dadas funções muito além das que incumbiam ao Estado Liberal, deixando o direito produzido pelo Estado de "meramente prestar-se à harmonização de conflitos e à legitimação do poder, passando a funcionar como instrumento de implementação de políticas públicas (GRAU, 2012, p. 19.)", dentre as quais a compatibilização da atividade econômica com a preservação do meio ambiente.

Dando lugar a esse papel integrador, o Estado detém o poder de polícia, competindo-lhe "restringir o uso e o gozo da liberdade e da propriedade em favor do interesse da coletividade”. (CARVALHO FILHO, 2007, p. 68)

As próprias normas que regulamentam as atividades econômicas trazem em seu bojo uma série de requisitos materializadores do poder de polícia na seara ambiental, que devem ser cumpridos para que se possa iniciar o desenvolvimento da respectiva atividade, instituindo as competências fiscalizatórias e sancionatórias para os casos de descumprimento.

Exemplarmente, menciona-se o Código de Minas (Decreto-lei n ${ }^{\circ} 227$, de 28 de fevereiro de 1967), segundo o qual, havendo descumprimento das obrigações Em Debat: Rev. Dig., ISSNe 1980-3532, Florianópolis, n. 9, p. 74-89, jan-jun, 2013. 
decorrentes das autorizações de pesquisa, das permissões de lavra garimpeira e do licenciamento, o titular estará sujeito a advertência, multa e até mesmo à caducidade de seu título. O código determina, ainda, que as atividades de fiscalização (art. $3^{\circ}$, III, c/c art. 88) e de aplicação de sanções (art. 63, $\S 1^{\circ}$ ) são de competência do Departamento Nacional de Pesquisa Mineral.

Neste ponto, importante invocar a Resolução Conama 237/97, segundo a qual a licença ambiental é:

Ato administrativo pelo qual o órgão ambiental competente estabelece as
condições, restrições e medidas de controle ambiental que deverão ser
obedecidas pelo empreendedor, pessoa física ou jurídica, para localizar,
instalar, ampliar e operar empreendimentos ou atividades utilizadoras dos
recursos ambientais consideradas efetiva ou potencialmente poluidoras ou
aquelas que, sob qualquer forma, possam causar degradação ambiental.
(Art.1 $1^{\circ}$, inciso II, Resolução Conama $\mathrm{n}^{\circ}$ 237/97)

Verifica-se, portanto, que a licença ambiental é uma autorização emitida pelo órgão público competente, com o estabelecimento de imposições a serem observadas pelo empreendedor, sob pena de (1) aplicação de multa; (2) embargo de obra; (3) não renovação das licenças ambientais etc. Nos termos de cartilha formulada pelo Tribunal de Contas da União:

Ela é concedida ao empreendedor para que exerça seu direito à livre iniciativa, desde que atendidas as precauções requeridas, a fim de resguardar o direito coletivo ao meio ambiente ecologicamente equilibrado. Importante notar que, devido à natureza autorizativa da licença ambiental, essa possui caráter precário. Exemplo disso é a possibilidade legal de a licença ser cassada caso as condições estabelecidas pelo órgão ambiental não sejam cumpridas. (TCU, 2007, p. 10)

No caso concreto, está-se diante de hipótese clara de incidência do poder de polícia estatal, tendo em vista que salta aos olhos o descumprimento reiterado pela empresa das condicionantes do licenciamento de implantação do Projeto Minas-Rio. A partir da análise do julgamento do recurso das condicionantes efetuado pela "Secretaria de Estado de Meio Ambiente e Desenvolvimento Sustentável”, em conjunto com a "Superintendência Regional de Regularização Ambiental" - Jequitinhonha (CIMOS, 2012), conclui-se que, das cento e sete condicionantes impostas na fase de licenciamento de implantação, até a data de 24/03/2011, doze já haviam sido descumpridas, ao passo que as comprovações do cumprimento de vinte e três tinham sido entregues fora do prazo.

Dentre as condicionantes descumpridas está a que impunha ao empreendedor "executar monitoramento arqueológico de todas as intervenções do empreendimento, com a remessa de relatórios bimestrais ao IPHAN e à Supram Jequitinhonha". 
Se, nos termos do inciso I, do art. $3^{\circ}$ da Lei Complementar $n^{\circ} 140$, de 08 de dezembro de 2011, "proteger, defender e conservar o meio ambiente ecologicamente equilibrado" é dever dos entes federados responsáveis pelo licenciamento, não atendida condicionante ligada à proteção de patrimônio arqueológico, deve haver imposição de penalidade, com a imediata paralisação das obras.

\section{O poder de polícia ambiental e participação da sociedade}

O Estado, conforme se afirmou, detém o poder de regulamentar as atividades econômicas, permitindo ou não a instalação de determinado empreendimento. Todavia, tal prerrogativa, não pode ter lugar sem que seja ouvida a população atingida. É que a gestão do interesse público deve se realizar em parceria com a sociedade civil, a partir de seus interesses e visando à concretização do bem comum, sob pena de se dar vazão a apenas parte das determinações constitucionais.

O cidadão não é mais apenas aquele que vota, mas o que vota, trabalha, tem
saúde, lazer e dignidade. A democracia não mais se confunde com seus
instrumentos. Democracia não é voto, mas sim a possibilidade de o povo
permanentemente indicar a direção que deve tomar o Estado. (...) Desta
forma, não há democracia apenas com o voto, se não existem poderes do
Estado (...) que sejam sensíveis à vontade do povo e da sociedade civil
organizada, que deve ser expressa diariamente. (MAGALHÃES, 2002, p.31.)

O resultado que decorre da postura de não participação de todos os grupos sociais nas discussões acerca dos rumos das atuações governamentais é aquele identificado por Boaventura de Souza Santos como "regresso do colonizador" (SANTOS, 2010, p. 45). O Estado, ao não exercer dialogicamente o seu papel de regulador da vida econômica, não operando em busca dos interesses dos grupos sociais dependentes de sua atuação por se constituírem como a parte mais fraca nas relações sociais, termina por dar a "poderosos atores não-estatais (...) controle sobre as vidas e o bem-estar das vastas populações”. E continua:

A obrigação política que ligava o sujeito de direito ao Rechtstaat, o Estado
constitucional moderno, que tem prevalecido deste lado da linha, está a ser
substituída por obrigações contratuais privadas e despolitizadas nas quais a
parte mais fraca se encontra mais ao menos à mercê da parte mais forte. Esta
forma de governo apresenta algumas semelhanças perturbadoras com o
governo da apropriação/violência que prevaleceu do outro lado da linha.

Na passagem em referência, o sociólogo português identifica a situação como a submersão do fascismo social, caracterizado por um "regime social de relações de poder 
extremamente desiguais que concedem à parte mais forte o poder de veto sobre a vida e o modo de vida da parte mais fraca".

A situação em Conceição do Mato Dentro é tão grave que a realidade impôs à população a necessidade de criação de uma Rede de Acompanhamento Socioambiental (REASA), que se trata de um

[...]grupo de discussão e ação composto por representantes de instituições públicas e sociedade civil organizada que através de reuniões periódicas tanto física quanto virtualmente pretendem acompanhar e propor soluções para conflitos e impactos na área socioambiental. [...] A Rede foi criada por iniciativa da sociedade civil organizada, sem qualquer participação do Estado, a partir da necessidade de se acompanhar responsabilidades e impactos socioambientais de empreendimento minerário em Conceição do Mato Dentro e região. (MINAS GERAIS. Ministério Público)

As denúncias que ocorrem principalmente nas audiências públicas da (REASA) são de violações a direitos humanos individuais, dentre eles a liberdade de ir e vir, propriedade, integridade física, e também de violações de direitos coletivos, como por exemplo, o direito a um meio ambiente equilibrado devido à contaminação da água e desmatamento da Mata Atlântica. Não se pode deixar de reconhecer o mérito da rede, contudo, a ausência do poder público acaba por tornar menos efetivas do que poderiam ser as discussões realizadas no referido fórum.

Verifica-se que o Estado Brasileiro ao permitir a instalação de empreendimentos como o Projeto Minas-Rio, sem consultar previamente as populações diretamente por ele atingidas, partindo do pressuposto de que os resultados para os investidores e para a economia de mercado justificam por si só o empreendimento, efetiva apenas parte do texto constitucional, abandonando fundamentos da República, como a cidadania e a dignidade da pessoa humana (CR/88, art. $1^{\circ}$, II e III). Ignora que o desenvolvimento sustentável determina que o crescimento econômico seja calcado na superação do subdesenvolvimento com a promoção de uma existência digna para as gerações presentes e as futuras, em um ambiente equilibrado.

\section{Conclusão}

O texto constitucional, como demonstrado, traz em seu bojo uma série de princípios que devem nortear a atuação estatal, cabendo a este ente a regulação e fiscalização da atividade econômica, proteção do meio ambiente e garantia aos direitos individuais e coletivos e do desenvolvimento nacional. Tudo isso com vias à construção de uma sociedade mais democrática, igualitária e justa. 
O Estado Brasileiro, ao permitir a instalação de empreendimentos como o Projeto Minas-Rio sem a devida fiscalização e participação das populações diretamente por ele atingidas, partindo do pressuposto de que os resultados para os investidores e para a economia de mercado justificam por si só o empreendimento, viola preceitos do texto constitucional, principalmente aqueles que dizem respeito aos direitos individuais e coletivos.

O que se tem percebido, contudo, é que o caminho tomado pelo Estado brasileiro em relação às empresas mineradoras tem ido à contramão de tudo o que dispõe o texto constitucional, e inclusive à contramão do discurso utilizado por ele em conjunto com o particular para justificarem a implantação da atividade.

Verifica-se, assim, que o Estado não tem cumprido sua função de regulador/fiscalizador da atividade econômica e protetor do meio ambiente. Pelo contrário, parece estar contribuindo para que as empresas privadas, com maioria de capital estrangeiro, como é o caso da "Anglo American", usufruam de nossas riquezas sem nenhum ônus, que tem recaído somente em cima da população. Pode-se notar, ainda, que a falta de espaços em que seja garantido o debate entre comunidade-Estadoempresa tem contribuído para atrasar a construção de uma sociedade livre, justa e igualitária, e o tão almejado desenvolvimento nacional, como prevê o texto constitucional.

\section{Referências}

BRASIL não é mais a sexta economia mundial. O Economista. 21 dez. 2012. Disponível em: <http://www.oeconomista.com.br/brasil-nao-e-mais-a-sexta-economiamundial/>, acesso em: 07 maio 2014.

BRASIL, Cláudia. Especial Mineração - Benefícios e prejuízos para os municípios que dependem da exploração. Câmara dos Deputados. 06 fev. 2012. Disponível em: <http://www2.camara.leg.br/camaranoticias/radio/materias/reportagemespecial/409092-especial-mineracao---beneficios-e-prejuizos-para-os-municipios-quedependem-da-exploracao.html> acesso em: 07 maio 2014.

BRASIL, Constituição Federal de 1988.

BRASIL, Decreto-lei nº 227, de 28 de fevereiro de 1967. 
BRASIL, Lei Complementar $n^{\circ}$ 140, de 08 de dezembro de 2011.

BRASIL, Resolução Conama 237/97.

BRASIL. Tribunal de Contas da União. Cartilha de licenciamento ambiental. $2^{\mathrm{a}}$ ed. Brasília: TCU, $4^{a}$ Secretaria de Controle Externo, 2007. 83 p. Disponível em: < http://portal2.tcu.gov.br/portal/pls/portal/docs/2059156.PDF>, acesso 07 maio 2014.

CARVALHO FILHO, José dos Santos. Manual de Direito Administrativo. $18^{\text {a }}$ edição. Rio de Janeiro: Lumen Júris, 2007.

CLARK, Giovani e Juliana Benício Xavier. A Repetida Política Econômica Indutora: A redução do IPI no setor automobilístico como exemplo de violação aos Comandos Constitucionais. In Direito e economia [Recurso eletrônico on-line]/organização CONPED/UFF; coordenadores: Sônia Barroso Brandão Soares, Giovani Clark, Felipe Chiarello de Souza Pinto. Florianópolis: FUNJAB, 2012.

COELHO, Tádzio Peters. Mineração e dependência no quadrilátero ferrífero. Intratextos, Rio de Janeiro, Número Especial 03, pp.128-146, 2012. Disponível: < file:///C:/Users/loja1304/Downloads/3140-11996-1-PB\%20(2).pdf >, acesso em: 07, maio 2014.

FREITAS, Juarez. Discricionariedade Administrativa e o Direito Fundamental à Boa Administração Pública. São Paulo: Malheiros. 2007. $2^{a}$ edição.

Sustentabilidade Direito ao Futuro. Belo Horizonte: Editora Fórum, 2011.

GRAU, Eros Roberto. A Ordem Econômica na Constituição de 1988. 15ª Edição. São Paulo: Malheiros, 2012.

MACHADO, Paulo Affonso Leme. Direito Ambiental Brasileiro. $13^{\text {a }}$ Edição. São Paulo: Malheiros, 2005.

MAGALHÃES, José Luiz Quadros de. Direito Constitucional - Tomo II. Belo Horizonte: Mandamentos, 2002.

Reflexões sobre o novo constitucionalismo na América do Sul: Bolívia e Equador, José Luiz Quadros de Magalhães. 01 nov. 2011. Disponível em: 
$<$ http://joseluizquadrosdemagalhaes.blogspot.com.br/2011/11/802-reflexoes-sobre-onovo.html>, acesso em: 07, maio 2014.

MARINI, Ruy Mauro. Dialética da Dependência. Petrópolis: Ed.Vozes, 2000.

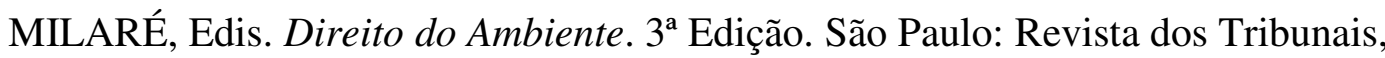
2004.

MINAS GERAIS. Ministério Público. Coordenadoria de Inclusão e Mobilizações Sociais (CIMOS). Disponível em: < http://pt.scribd.com/doc/109532833/JulgamentoRecurso-Condicionantes-Anglo-Li-Fase-II >, acesso em: 07 maio 2014.

Coordenadoria de Inclusão e Mobilizações Sociais (CIMOS). Disponível em: <http://cimos.blog.br/reasa/>, acesso em: 07 maio 2014.

MORAES, Alexandre de. Direito Constitucional. 26ª Ed. São Paulo: Atlas, 2010.

PALMA, Gabriel. Dependência das comodities ameaça economia, diz Palma. ABLA Associação Brasileira das Locadoras de Automóveis. Notícias do Mercado. Disponível em: <http://www.abla.com.br/dependencia-das-commodities-ameaca-economia-dizpalma/>, acesso em: 07 maio 2014.

PEREIRA, Denise de Castro e PEREIRA, Luciana Felício. Cenários Socioambientais em municípios com Mineração: Complexidades estratégicas e possibilidades transformadoras. In:___ I Seminário Internacional de Reconvenção de Territórios. 2012. Belo Horizonte/ MG.

PRADO Jr. Caio. História Econômica do Brasil. Ed. Brasiliense: São Paulo, 1984.

REVELLI, Philippe. Vale, a multinacional dos conflitos. Le Monde Diplomatique Brasil, 01 out. 2010. Mineração. Disponível em:

<http://www.diplomatique.org.br/artigo.php?id=789>, acesso em: 07 maio 2014.

SANTOS, Boaventura de Sousa. Para além do pensamento abissal: das linhas globais a uma ecologia de saberes. In Epistemologias do Sull Boaventura de Sousa Santos, Maria Paula Meneses (org). São Paulo: Cortez, 2010.

SUNDFELD, Carlos Ari. Direito Administrativo para Céticos. São Paulo: Malheiros. 2012. 